\title{
Abuse and Neglect of the CQI Process
}

\section{Thomas E Catanzaro*}

American College of Healthcare Executives, CEO, Veterinary Consulting International, Australia

*Corresponding author: Catanzaro TE, American College of Healthcare Executives, CEO, Veterinary Consulting International, Australia, Tel: +610416285975; E-mail: DrTomCat@aol.com

Received date: April 11, 2016, Accepted date: June 23, 2016, Published date: June 27, 2016

Copyright: () 2016 Catanzaro TE. This is an open-access article distributed under the terms of the Creative Commons Attribution License, which permits unrestricted use, distribution, and reproduction in any medium, provided the original author and source are credited.

\section{Introduction}

The continuous quality improvement (CQI) process is based on the long-term practice commitment to establish pride as a goal for each individual's performance and empowering the staff to pursue excellence whenever the need is identified. Abuse and neglect are companion terms, as we use them in animal welfare, and can be used in evaluation of the CQI process; abuse requires proving the intent while neglect just evaluates the outcomes. As with most long-term operations, the lapse of time dulls the intensity of emphasis. While most quality practices that adopt CQI as a cornerstone value will not abuse the CQI principles, neglect can creep into the operation. While this may be due to multiple factors, the most common is that entrenched habits of the past resurface when the leadership emphasis goes away.

\section{Shake up your System}

The following areas of interest are often entrenched habits that must be shaken at the roots then recalibrated for the process of continuous quality improvement (CQI) to be accepted as an emerging practice value.

\section{Emphasis on short-term profits}

Americans want immediate gratification, while Australians fear the TALL POPPY SYNDROME, whether it be cafe food or practice management techniques. The current trend to control expenses to make profit can only work in practices that have poor management; most well-managed practices have expenses controlled within the first three business cycles. The profit increase from cost control does not make the "money pie" bigger, it only gives you a bigger piece at this one sitting. Well-managed practices already have cost control procedures and need to look at long-term income programs. This means the investment of time and money, usually longer periods of time for the transition than ever used before in the practice. The new income programs need to be considered long term because equipment, training, and client education usually will be required to make the emerging income center profitable. This is why the recent emphasis by neophyte consultants to UP-SELL and/or CROSS-SELL will usually come back to kill a practice's community reputation.

\section{Management by fear}

The traditional retrospective performance evaluation promotes short-term performance at the expense of long-term planning, discourages risk taking, pits people against each other for common rewards, and undermines the teamwork required to improve the practice performance. The insidious effect is an increased reliance on arbitrary merit pay numbers rather than team performance. Some veterinarians dread making judgments of their staff; CQI is an answer to this fear. Competition is not required for excellence, as demonstrated by historical figures like Einstein, Bach, or Shakespeare. People work for themselves far better than working for an employer. The job of a leader is to reduce limits, reduce variation in accepted processes, and to increase the capabilities of the people he influences.

\section{Decisions based on numbers alone}

The use of easy to get figures is a starting point of management, as is participative management techniques with the staff relationships. Continuous quality improvement (CQI) requires a stretch beyond these established habits. The effect of a happy client on new client referrals is hard to measure and a great variable, but it is critical to success in an overpopulated veterinary health care community. The value of effective communication and problem resolution on the litigious nature of the practice client base is impossible to measure, unless it goes astray. Pride can make a difference in these factors, but there are no numbers that reflect the pride of performance that a staff member feels after a hard day at the practice grind.

\section{Inability to accept change management}

The good news of continuous quality improvement (CQI) must be preceded by the bad news that something is wrong. The discomfort of accepting this fact should be cause for change of habits, not change of practice staff. The person elevating a problem to the level of attempting a solution is to be commended, not chastised and defined out of existence; this is where the "soulcrusher" has a major impact, in making people feel dumb for having a new or improved idea. A change strategy is based on the identification of a problem, a frustration, or a practice distraction, followed by developing dissatisfaction and discomfort about the discovery. This new discomfort should lead to evaluation of alternatives to reach new goals and objectives, systematic education and training of ALL STAFF involved, implementing a test plan, checking the effects of the test plan, then taking the appropriate leadership action to establish the new habits within the practice staff and within the daily operations.

\section{Lack of constancy}

The privilege of the practice owner to state a set of rules and procedures then grant exceptions is an American as well as Australian and New Zealand right. It is also a reason that veterinary-ownership management has been by-passed by emerging industrial countries. If the staff cannot trust the values and standards of the practice and ownership to support their decisions, they will not make workmanship decisions; they will play it safe. Dedication to the principles of CQI must be widespread, constant, and promoted on a regular basis. It is not enough just to announce the CQI commitment, since all employees 
have seen the great ideas come and go during the life of a practice; they need proof. One way is money, money for training and equipment, or the cost of stopping an operational process that violates CQI values. The leadership must take the time to explain and discuss the CQI process in full.

When pursuing continuous quality improvement (CQI), a good leader will not get lost in the trivia of the past parameters, but rather, set new team goals that elicit a move toward greatness and pride.

A great leader may even use a MIND-MAP process (e.g., Tony Buzon's text or Volume 3, Building the Successful Veterinary Practice: Innovation \& Creativity) to achieve the new and/or revised programs.

\section{Neglect of long-range planning}

Even with a clear and achievable long-range plan, practices get derailed because of personnel problems, economic recessions, or other "emergencies" not in the plan. Many times the principles of CQI are forgotten because of frivolous attention to insignificant details, such as someone who left early one day because their work was done. If the pride in performance and outcome are present, is it really important when the minutes tick off the time clock? What is the excuse/reasoning used when doctors come in late or take an extended lunch break; are they applicable to all personnel?

\section{Adding toys instead of commitment}

The addition of a new endoscope does not increase the staff commitment to continuous quality improvement, although it is something to boast about at the local VMA meeting. A new dental base or new anesthesia machine does not convey the need to the client, that is done by staff members on a regular basis, by phone, at the reception desk, in the consult room, or socially out in the community; it is called practice pride (clients equate staff pride with quality, and will usually readily pay extra for that peace of mind). Equipment is secondary to the health care delivery commitment of a dedicated team, but can add pride if they are the beneficiaries of that new equipment.

\section{Blaming others for the problem}

Too often, a practitioner blames the environment, the competition, or even the staff for a problem that has been identified; the "soulcrusher" seldom sees the negative effect of the blaming process (blaming is only the neglect of the accountability to find a resolution). The simple fact is that only 15 percent of the problems are influenced by the staff of most any healthcare facility, the other 85 percent is due to the system or the management of the system. Quality control and quality assurance are based on discovering errors in the past, assigning blame, and establishing a quick-fix of the discovery. CQI is based on responding to the future changes before they occur by changing habits and procedures to be more responsive to the emerging demands of clients, staff, and health care providers.

\section{Defining quality too narrowly}

By defining the end result of CQI in terms of healthcare services and technological advancements, entire segments of the staff begin to see themselves as secondary to the effort. The leadership communication that stresses that no person is too low in the organization to be excluded and no person is too privileged to be exempt from evaluation and change is the winning secret for continuous quality improvement. The definition must include the clinical outcome, service to the client, management structure, staff process, and pride in the process used in the delivery at every level of the practice.

\section{In Practice}

To consider anything less than quality performance in healthcare delivery seems unthinkable. Quality has always been an explicit goal in veterinary medicine, so why is it being rediscovered? Why do clients price shop, and why do colleagues offer discounts if quality is explicit? The answer is attitude versus behavior, theory versus reality, rhetoric versus action. Managers do things right; leaders do the right things.

Continuous quality improvement (CQI) is not just something the veterinarian buys into to improve the quality or productivity, although these are outcomes of the process. CQI is a way of practice life that must be lived consistently, day by day. The ownership must "walk the talk" of organizational values and purpose (you can review more in the monograph from the VIN Bookstore on "Organizational Behavior"). Genuine leaders create, embody, and communicate the vision, values and sense of mission needed to establish pride in the practice. There are no short cuts in developing continuous quality improvement as a practice process. Everyone must just "do it!" 